\title{
CLIMA E TURISMO NUM CONTEXTO DE MUDANÇAS CLIMÁTICAS
}

RaQuel Machete ${ }^{1}$

\begin{abstract}
Resumo - A disseminação da prática turística é um fenómeno recente, especialmente marcado a partir da década de 60 do século passado. Mais recente ainda é o estudo sistemático das relações entre turismo e clima. Na abordagem teórica acerca da motivação turística, o clima, visto como um bem ou a prestação de um serviço, transforma-se num recurso passível de ser avaliado. Neste texto, exemplificam-se várias tentativas para quantificar o "recurso climático" na determinação do potencial turístico de uma região e sintetizam-se os conhecimentos sobre a importância do clima na motivação dos turistas. Além disso, o turismo é um dos sectores económicos em que se antecipa que as alterações climáticas venham a ter bastante impacto, devido a modificações do clima nos locais turísticos; por outro lado, as próprias práticas turísticas contribuem para intensificar as alterações climáticas, devido ao aumento de emissão de gases com efeito de estufa. Na segunda parte, abordam-se as possíveis interacções entre as alterações climáticas e o turismo, bem como possíveis medidas de mitigação e adaptação.
\end{abstract}

Palavras-chave: Turismo, motivação turística, potencial climático-turístico, alterações climáticas, mitigação, adaptação.

\begin{abstract}
Climate and tourism in the context of environmental change. The dissemination of tourism is a recent phenomenon that became particularly important in the 1960 s and the systematic study of its relation to climate is even more recent. When included in the theoretical approaches to tourism motivation the climate, seen as an asset or service, becomes a resource that can be evaluated. This paper looks into various attempts to quantify the "climate resource" in the determination of the tourism potential of a given region and summarizes the importance of climate on tourists' motivation. Tourism is one of the economic sectors where climate change is expected to have a substantial impact due to climate alterations in tourist locations. Conversely, tourism activities contribute to intensify climate changes due to an increase in greenhouse gas emissions. The second part of this paper addresses the possible interactions between climate change and tourism, as well as possible mitigation and adaptation measures.
\end{abstract}

Keywords: Tourism, tourism motivation, climatic-tourism potential, climate change, mitigation, adaptation.

1 Investigadora do Núcleo CliMA (Clima e Mudanças Ambientais) do Centro de Estudos Geográficos da Universidade de Lisboa. E-mail: raquelmachete@gmail.com 
Résumé : Climat et tourisme dans un CONTEXTE DE Changements ClimatiQues. La dissémination des pratiques touristiques est un phénomène récent qui s'est surtout intensifié à partir des années 1960. L'étude systématique des relations existant entre tourisme et climat est plus récente encore. D'un point de vue théorique, en ce qui concerne la motivation touristique, le climat, vu comme un bien ou comme une prestation de service, devient une ressource passible d'évaluation. On présente diverses tentatives de quantification de la « ressource climatique » pour déterminer un potentiel touristique régional, et on indique les connaissances actuelles portant sur l'influence du climat sur le choix des touristes. Le tourisme est l'un des secteurs économiques pour lesquels on pense que les altérations climatiques dans les lieux de tourisme auront de l'importance. Et les pratiques touristiques elles-mêmes contribuent à l'intensification des altérations climatiques par l'augmentation des émissions de gaz à effet de serre. On aborde enfin les interactions entre les altérations climatiques et le tourisme, ainsi que d'éventuelles mesures d'atténuation et d'adaptation.

Mots clés: Tourisme, motivation touristique, potentiel climatico-touristique, altérations climatiques, atténuation, adaptation.

\section{INTRODUÇÃO}

O número de chegadas de turistas a todas as fronteiras do mundo, que não ultrapassava 25 milhões por volta de 1950 (World Tourism Organization [UNWTO] 2002), atingiu em 2009 os 880 milhões (UNWTO, 2010). Para este crescimento concorreram tanto a crescente mobilidade permitida pela inovação nos meios de transporte e nas tecnologias de comunicação e informação, como a prosperidade económica e a expansão do tempo dedicado ao lazer (Viner e Agnew, 1999; Cavaco e Simões, 2009).

Tem sido gradual a tomada de consciência do peso e da dinâmica de crescimento do sector turístico, que é hoje uma força motriz da economia. Sendo o turismo um fenómeno que só se disseminou amplamente após a Segunda Guerra Mundial, o seu estudo não está, de acordo com Scott et al. (2009), tão desenvolvido quanto o de outras actividades económicas. Os autores apontam o fraco investimento governamental na investigação das dimensões ambiental e social do turismo, cingindo-se a maior parte dos países ao estudo do marketing da sua oferta turística ou à monitorização do número de visitantes e dos gastos por estes efectuados.

A procura turística tem sido abordada nas mais variadas perspectivas, no intuito de compreender o complexo jogo de factores que justifica esta prática. Nesta revisão bibliográfica, evidenciar-se-á de que forma o clima constitui uma força motivacional para o turismo e também que relações se podem estabelecer entre o turismo e as alterações climáticas; além disso, sistematizam-se algumas das medidas de adaptação necessárias para atenuar os impactes negativos das alterações climáticas, e para tirar proveito de potenciais oportunidades geradas por elas. No caso destas últimas, serão sobretudo referidas as potencialidades ambientais e climáticas para a prática turística, nomeadamente no campo da bio-climatologia.

A deslocação motivada pela procura de condições climáticas já se observava em períodos históricos muito recuados (Besancenot, 1990; Fagence e Kevan, 1998; Perry, 1997). Datam da Mesopotâmia e Antigo Egipto os primeiros registos de êxodos, como meio de fugir às epidemias e à insalubridade das grandes urbes. Existem também relatos da prática de migrações sazonais por parte das elites ateniense e romana, que se refugiavam 
nas praias e colinas próximas para escapar ao calor e à poluição das áreas urbanas (Cavaco, 2008). Ao longo do tempo, cada elite política dispôs de locais de evasão próximos das diversas capitais. É excepção o Período Medieval, quando o retrocesso da civilização urbana estancou esta primeira vaga de turismo climático, inaugurando, não obstante, um novo móbil para os fluxos humanos: a peregrinação aos locais sagrados (Besancenot, 1990; Fagence e Kevan, 1998; Dias, 2009).

$\mathrm{O}$ progresso da Medicina levou à tentativa de estabelecer um vínculo mais preciso entre as condições climáticas e a saúde. De acordo com Besancenot (2001), a "utilização" do clima com fins preventivos ou curativos foi especialmente pronunciada entre o fim do século XVIII e o início do século XX. Em meados do século XVIII, quando os efeitos benéficos do ar marítimo, do oxigénio e do iodo começaram a ser conhecidos e divulgados, a par das já então reconhecidas propriedades terapêuticas da água do mar, nasce a cidade balnear, frequentada, neste primeiro momento, pela aristocracia (Brito-Henriques e Lousada, 2010). É essa mesma aristocracia que institui a cidade de Inverno, de que é exemplo a Riviera Francesa, uma vez mais justificada pela busca de regiões de clima mais ameno (Cavaco, 2008; Dias, 2009). A valorização da água do mar e do clima como elementos naturais benéficos evidenciam o reconhecimento da biometeorologia e da climatologia médica no século XIX (Cavaco, 2008). No século XX, o aproveitamento do clima com fins curativos é progressivamente preterido em favor da nova medicina científica e farmacêutica (Cavaco, 2008).

A continuidade da procura de destinos que reuniam características climáticas e paisagísticas favoráveis estimulou o florescimento de actividades de carácter mais lúdico associadas ao turismo e à recreação. A "invenção" da praia dá continuidade à procura dos refúgios balneares instituídos primariamente por motivos terapêuticos (Cavaco, 2008; Brito-Henriques et al., 2010). Embora a crença nas propriedades benéficas da exposição solar não seja hoje em dia unânime, o século XX assistiu ao estabelecimento de uma tendência de procura de sol, que explica que o período estival se tenha tornado a estação turística preferencial (Besancenot, 1990; Fagence e Kevan, 1998). A preferência por uma tez branca, que explicava que a exposição solar fosse evitada, é substituída, a partir de meados do século XX, pela valorização da pele bronzeada (Besancenot, 1990; Perry, 1997; Brito-Henriques et al., 2010). Nesse século, de profundas mudanças sociais, ocorreram transformações de fundo também no que concerne à procura turística, nomeadamente no volume de praticantes. A atribuição de férias pagas aos trabalhadores dos países desenvolvidos, depois da segunda guerra mundial, a par dos factores acima enumerados, veio massificar progressivamente a prática turística (Besancenot, 1990).

Profundamente globalizado, mas também altamente circunscrito - na medida em que se localiza preferencialmente em destinos específicos (Wall, 2007) -, o turismo é bastante influenciado por condições estruturais, nomeadamente pelos recursos naturais dos destinos, tendências dentro do próprio sector, mudanças de maior profundidade e de longo prazo (afectadas pelas alterações climáticas), assim como por factores conjunturais, como crises económicas, problemas de segurança ou flutuações do preço dos combustíveis (Cavaco e Simões, 2009).

A escolha de certos destinos em detrimento de outros é também explicada por factores de ordem psicológica, que interferem com o desejo de viajar. As abordagens teóricas da motivação turística são de dois tipos: as que dão especial relevância aos mecanismos psicossociais subjacentes à motivação turística (teorias de micro nível) e as perspectivas sociológicas, ou de macro nível, que enfatizam a importância das condicionantes estruturais nas escolhas dos turistas (Dias, 2009; Lubbe, 1998; Neves, 2008). 
No quadro das explicações alicerçadas nas condicionantes estruturais, que mais directamente se prendem com o âmbito de análise do presente texto, as principais abordagens propostas são o modelo de "push-pull" (Dann, 1977, citado in Dias, 2009), a procura da autenticidade (McCannell, 1973, citado in Dias, 2009) e a procura de um "centro" espiritual (Cohen, 1979, citado in Dias, 2009).

É no modelo "push-pull" que é referido o clima. Partindo da teoria de Maslow da hierarquia das necessidades (1959, citado in Dias, 2009 e Neves, 2008), este modelo propõe a existência de duas diferentes forças, que se articulam para determinar as decisões de viagem: um conjunto de factores que desencadeiam a vontade de viajar (push) e outro conjunto de factores que caracterizam um determinado destino e lhe conferem atractividade (pull). As contribuições de autores como Dann (1977, 1981, citado in Lubbe, 1998), Chon (1989, citado in Lubbe, 1998), ou Lubbe (1998) sugerem a conceptualização representada na figura 1 .

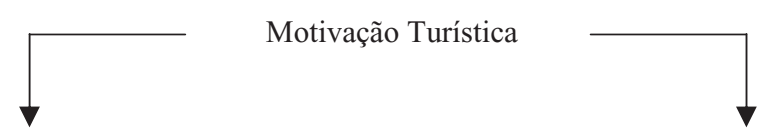

Push (Necessidades humanas)

- Fisiológicas

- Sentimento de segurança

- Sentimento de pertença

- Realização

- Conhecimento/educação

- Estética
Pull (Atributos que conferem atractividade ao destino)

- Estáticos - paisagem, clima, cultura

- Dinâmicos - acomodação, gastronomia, serviços, acessibilidade

- Decisões correntes - preço, promoções

Fig. 1 - Modelo das duas forças motivacionais: predisposição para viajar - factores de atractividade do destino (push-pull) baseado nas contribuições teóricas de Dann (1977), Chon (1989) e Lubbe (1998).

Fig. 1 - Two motivational drivers model: willingness to travel - attractions of a destination (push-pull), based on Dann's (1977), Chon's (1989) and Lubbe's (1998) contributions.

Alguns autores propõem outras categorizações, nomeadamente Fakeye e Crompton (1991, citado in Lubbe, 1998), que identificam seis ordens de factores "pull":

- Oportunidades sociais e atracções;

- Recursos naturais e culturais;

- Alojamento e transporte;

- Infra-estrutura, alimentação e hospitalidade;

- Amenidades físicas e actividades de recreio;

- Bares e entretenimento nocturno.

\section{O CLIMA ENTRE OS FACTORES DE MOTIVAÇÃO TURÍSTICA}

Os recursos naturais, elencados entre os factores de motivação turística, não só contemplam o clima, mas também são por ele condicionados (De Freitas, 2003; Perry, 2005; Wilbanks, 2007). As alterações climáticas poderão, neste sentido, desencadear algumas modifi- 
cações, nomeadamente a perda de biodiversidade, a degradação estética da paisagem, a alteração do ciclo de produção agrícola (que afecta, por exemplo, o turismo vitivinícola), a erosão do litoral, ou o aumento da incidência de doenças transmitidas por vectores (organismos, tais como mosquitos ou pulgas, que transmitem doenças entre hospedeiros; Simpson, 2007; Simpson et al., 2008).

Por outro lado, a concretização de determinadas actividades associadas ao recreio depende muito das condições climáticas e meteorológicas. Por exemplo, uma estância de esqui, mesmo com todas as estruturas e equipamentos físicos, não pode prescindir da neve como recurso-chave.

O peso dos vários factores identificados nestas abordagens teóricas varia, naturalmente, em função do tipo de procura turística. Como Gómez-Martin (2005) enfatiza, quase todas as formas de turismo fazem uso dos recursos naturais. No entanto, viagens de lazer, de negócios, ou para tomar parte numa conferência científica responderão de forma diferente às condicionantes climáticas. Neste sentido, Smith (1993, citado in Perry, 1997) distingue turismo sensível ao clima de turismo dependente do clima; o primeiro tipo verificase quando o clima não determina a decisão de viajar, mas interfere na maneira como a experiência turística é vivida, nomeadamente afectando a participação em actividades de recreação; no segundo tipo, a própria viagem é determinada pela atractividade e fiabilidade das condições climáticas. Como exemplos de turismo dependente do clima, cite-se o turismo de neve, o eco-turismo e o turismo de sol e mar, muito exigentes em relação às condições climáticas, as quais condicionam também a paisagem e a biodiversidade (Scott et al., 2009). Por outro lado, quando se considera o turismo sensivel ao clima, a atractividade de um destino urbano é-lhe conferida por outros pressupostos, como as características culturais e o património. Não obstante, a realização das actividades ligadas a este tipo de turismo também é condicionada pelas condições atmosféricas - nomeadamente, a não ocorrência de precipitação ou de calor excessivo. Assim, ainda que não seja um impedimento à realização da viagem, o clima terá certamente um importante peso na satisfação do turista (Perry, 1997).

Observando, quer a dinâmica histórica do fenómeno turístico, quer a tentativa de o conceptualizar, não se pode deixar de constatar a importância de que o clima se reveste para esta prática.

\section{O CLIMA COMO RECURSO}

O clima existe independentemente da sua exploração por parte dos agentes turísticos, transformando-se num recurso ao ser incorporado num bem ou na prestação de um serviço (Gómez Martin, 2005). Trata-se de um recurso com características muito particulares provido de um carácter simultaneamente permanente e renovável (Besancenot, 1990). Isto é, o "consumo" turístico não esgota esse recurso, ainda que haja uma evidente apropriação por parte dos agentes que dele se servem para valorizar o seu usufruto. Está também desigualmente repartido no globo e, mesmo numa localização particular, está sujeito a grande variabilidade interanual, estacional ou inter diária; não é passível de ser transferido ou armazenado e o seu usufruto no momento oportuno obriga a que o "consumidor" se desloque (Besancenot, 1990).

Matzarakis (2006) enfatiza a influência do clima e do estado do tempo nas três fases de uma viagem: antes, durante e depois. Isto é válido quer para os turistas, quer para a indústria turística. Na perspectiva do turista, o clima revela-se particularmente importante no momento 
anterior à viagem uma vez que, como se viu atrás, o clima expectável influi na decisão de viajar e na escolha do destino. Durante a estadia é, contudo, o estado do tempo que vai determinar a experiência do turista, nomeadamente a reunião de determinadas condições para as práticas e actividades antecipadas. A percepção posterior que o turista retém da estadia resulta do confronto destes dois elementos, isto é, o clima expectável e o estado do tempo que, com efeito, se experimentou.

Para todas as entidades da indústria turística, há uma necessidade óbvia de informação fiável acerca das condições climáticas das várias regiões (Perry, 1997; De Freitas, 2003).

Uma importante parte dos equipamentos relacionados com a actividade turística e de recreação - hotéis, estâncias de esqui, marinas, campos de golfe ou outros - exigem grandes investimentos em capital fixo. A realização destes investimentos implica uma confiança no retorno (Matzarakis, 2006).

A par da localização geográfica, da topografia, da paisagem, da fauna e da flora o clima e o estado do tempo constituem o recurso-base natural de um local, para a prática de recreação e turismo. Tratando-se de um recurso para o turismo, o clima é passível de ser classificado numa escala (De Freitas et al., 2008): têm sido sugeridos vários métodos para avaliar a influência integrada dos parâmetros climáticos na actividade turística, frequentemente sob a forma de diferentes índices climáticos, de complexidade variável. Os resultados obtidos com estes índices devem ser interpretados como indicações do potencial turístico de um destino, num período específico do ano.

Besancenot (1990, p.47 e seguintes) descreve índices elementares, propostos por Burnet (1963), Hughes (1967), Davis (1968), entre outros. Os mais usuais assentam em operações aritméticas com valores de elementos climáticos, tais como a duração da insolação, a temperatura e a precipitação, ou número de dias de chuva. Por norma, para o turismo balnear, considera-se um potencial turístico tanto mais elevado quanto mais soalheiro, quente e isento de chuva for o estado do tempo, num determinado destino e período. Sarraméa (1980) desenvolveu o índice "climático marítimo" que, não rompendo com os índices precedentes, se distingue pelo número de indicadores climáticos, abrangendo, para além dos parâmetros acima enumerados, a temperatura da água do mar, a velocidade do vento, o nevoeiro, o gelo e a neve.

Mieczkowski (citado em Besancenot, 1990 e em De Freitas, 2008) desenvolveu, em 1985, uma das abordagens mais abrangentes desta primeira geração de índices climático-turísticos. Propôs o "Tourism Climate Index" (TCI), formulado a partir da combinação de sete variáveis: temperatura máxima diária $\left({ }^{\circ} \mathrm{C}\right)$, temperatura média diária $\left({ }^{\circ} \mathrm{C}\right)$, humidade relativa mínima diária $(\%)$, humidade relativa média diária $(\%)$, precipitação $(\mathrm{mm})$, duração diária de insolação $(\mathrm{h})$ e velocidade do vento $(\mathrm{km} / \mathrm{h})$. Ao contrário dos índices anteriores, não são feitas operações com valores das variáveis independentemente do tipo de unidades (o que se nos afigurava incorrecto), mas os valores de cada variável são divididos em classes, às quais é atribuída um índice $(\mathrm{de}-2 \mathrm{a}+5)$ decorrente da sua maior ou menor adequação para o turismo. O resultado final do índice decorre do somatório dos valores atribuídos às diferentes variáveis, ponderados segundo a sua importância para o turismo. O índice de Mieczkowski foi posteriormente utilizado por outros investigadores, nomeadamente por Morgan et al. (2000), ajustando-o para avaliar ambientes litorais, e por outros autores a fim de anteciparem os potenciais efeitos das alterações climáticas nos vários destinos internacionais (Morgan et al., 2000; Amelung e Viner, 2007). 
Não obstante a utilidade dos esquemas propostos na comparação das potencialidades climático-turísticas das regiões em análise, várias são as críticas levantadas a estas formulações teóricas:

a) A maioria dos índices é calculada a partir de parâmetros expressos em diferentes unidades de medida (graus Celsius, horas de insolação, volume de precipitação, entre outros), combinação muito criticada por alguns especialistas (Besancenot, 1990). O método de cálculo do TCI evita esses inconvenientes.

b) Uma grande parte dos índices baseia-se em médias mensais. Neste sentido, outra das limitações apontadas prende-se com o facto de essas médias raramente expressarem o clima tal como é sentido pelos turistas (Besancenot, 1990). Por exemplo, um Verão em que a precipitação, embora fraca, ocorra ininterruptamente, e em que se registem poucos dias de insolação, mas a temperatura se mantenha nos $23,5^{\circ} \mathrm{C}$, seria, de acordo com o TCI de Mieczkowski categorizado como aceitável. Porém, existem grandes diferenças quanto às condições climáticas percebidas como aceitáveis ou adequadas, em função, quer do tipo de turismo e actividades a desenvolver, quer das características do turista, de que são exemplo, a idade, o estado de saúde (Perry, 1997), ou mesmo ao clima da região de partida (Smith, 1990, citado in Wall, 2007).

c) Outra crítica apontada por De Freitas (2008) aos índices climático-turísticos é o facto de não estarem validados pelas opiniões dos turistas ou dos agentes de mercado do sector.

Besancenot $(1978,1985)$ propôs um método alternativo de avaliar o clima de forma integrada, através da classificação de tipos de tempo em função da sua adequação à actividade turística, tendo utilizado essa metodologia em vários sectores do litoral europeu. Este processo foi posteriormente adaptado ao estudo da climatologia turística do Funchal (Alcoforado et al., 1999) e da Praia Grande em Sintra (Paulo, 1997, Alcoforado et al., 2004; Andrade et al., 2007). Na aplicação deste método à Praia Grande, a relação entre tipos de tempo e utilização/frequência do espaço foi validada pela afluência à praia, através da contagem do número de viaturas no local e a utilização de equipamentos de restauração locais. Segundo Matzarakis (2006), na impossibilidade de utilização de dados diários, médias de 10 dias reproduzem com suficiente exactidão o clima a que o turista está sujeito, tal como foi feito no Funchal (Alcoforado et al., 1999).

Incorporando resultados recentes de abordagens multidisciplinares (climatologia, turismo, biometeorologia, gestão de recursos, psicologia, geografia), novas propostas surgiram no âmbito de uma segunda geração de índices, procurando aprofundar o conhecimento das relações clima-turismo numa perspectiva holística.

De Freitas (2003) considera que os turistas respondem ao efeito combinado de várias dimensões do clima, nomeadamente a dimensão térmica, física e estética. A dimensão térmica da influência climática engloba as variáveis atmosféricas, que têm efeitos térmicos no corpo humano: temperatura e humidade do ar, velocidade do vento e temperatura radiativa média e leva também em conta o nível de actividade física e o vestuário dos turistas. A dimensão física decorre de elementos meteorológicos específicos (tais como o vento e a chuva) que, directa ou indirectamente, afectam a satisfação do turista de uma forma não térmica. A dimensão estética, finalmente, prende-se com a percepção subjectiva do estado da atmosfera, que pode ser qualificado a partir de atributos como a nebulosidade, a radiação solar, a 
duração do dia ou a visibilidade. A percepção das condições atmosféricas desencadeia mecanismos de respostas variadas, que podem ir desde a mera alteração de comportamentos (substituindo, por exemplo, o passeio pedonal por um passeio de carro), o recurso a objectos ou equipamentos (abrigos, piscinas interiores, etc.), ou o ajuste do isolamento térmico do corpo (vestuário), até a reacções mais extremas, como a escolha de um destino turístico em detrimento de outro (De Freitas, 2003, 2008).

\section{ALTERAÇÕES CLIMÁTICAS E TURISMO}

\section{Impactos das alterações climáticas no turismo}

Foi analisada, nos pontos precedentes, a influência do clima e do estado do tempo no turismo, sintetizando alguma da informação que tem sido produzida, quer pela psicossociologia (mediante o estudo da motivação turística) quer pela bioclimatologia. Admite-se que o clima constitui um recurso chave para o turismo, na medida em que determina a adequação de um destino para uma série de actividades turísticas e de recreação. Constitui, dessa forma, um dos motores da procura turística.

Não obstante, até recentemente, tanto a indústria turística como a comunidade académica, pouco se tinham debruçado quer sobre os impactos das alterações climáticas na actividade turística quer, inversamente, sobre o peso que o turismo e actividades com ele relacionadas têm surtido nas mudanças ambientais globais (Scott et al., 2009). As alterações climáticas estão na ordem do dia. As últimas projecções do Intergovernmental Pannel on Climate Change (IPCC, 2007) apontam, por exemplo para o Sul da Europa, a elevação das temperaturas máximas, a maior frequência das ondas de calor e o acréscimo dos episódios de precipitação intensa, a par de períodos de seca mais longos e severos. Importa, portanto, perceber de que forma essas mudanças se reflectirão na competitividade e na sustentabilidade dos destinos turísticos (Wilbanks et al., 2007)

As mudanças induzidas na duração e qualidade das estações turísticas, especialmente em tipos de turismo mais dependentes do clima (turismo de sol e praia ou de "desportos de Inverno") podem comprometer a competitividade de determinado destino turístico e o lucro das empresas que aí promovem a actividade (Simpson et al., 2008; Scott, Freitas e Matzarakis, 2009). A bibliografia tem apontado no sentido de uma futura preferência de destinos localizados em latitudes mais elevadas, em detrimento de destinos turísticos populares, possivelmente mais penalizados pela projectada subida de temperatura, tais como o Mediterrâneo (Scott et al., 2009; Hamilton et al., 2003). Alguns autores (Viner e Agnew, 1999; Amelung e Viner, 2007; Ehmer e Heymann, 2008) antecipam a perda de competitividade desta região na estação estival, por ser nela que as condições climáticas mais se poderão deteriorar. Essa perda far-se-ia em benefício de áreas até agora menos procuradas, como o Norte e Ocidente da Europa. Não obstante a previsão de perda de atractividade do Mediterrâneo no Verão, os mesmos autores (Amelung e Viner, 2007), que utilizaram o TCI de Mieckzowski, concluíram que, durante a Primavera e o Outono, as condições climáticas serão extremamente favoráveis.

Quanto às regiões onde o turismo de Inverno é predominante, a projecção de significativos decréscimos na queda de neve leva a que se antecipe grande vulnerabilidade para destinos de "desportos de Inverno". É o caso dos Alpes Europeus - onde se estima que cada grau centígrado de aumento de temperatura no Inverno exija uma subida de $150 \mathrm{~m}$ para atingir o 
limite mínimo de neve adequado para as estâncias de esqui (UNEP, 2007) - e da América do Norte Oriental e Ocidental (Viner e Agnew, 1999; Ehmer e Heymann, 2008). De 1850 até aos dias de hoje, os glaciares suíços já perderam mais de um quarto da sua superfície. Hoje em dia, $85 \%$ das estâncias nesta região são viáveis. Porém, a ocorrência de alterações climáticas poderá reduzir em mais de $20 \%$ (entre 2030 e 2050) o número de estâncias que dispõe de neve suficiente, se o limite mínimo de neve subir doas actuais 1200 metros para os 1500 metros (Burki et al., 2007). A importância do sub-sector turístico dos desportos de Inverno nesta região, assim como o curto prazo em que se antecipa que estas alterações se verifiquem, justificam que as primeiras abordagens científicas sobre os efeitos das alterações climáticas (Wall, Harrison, Kinnaird, McBoyle e Quinlan, 1986, citado em Scott e Becken, 2010) fossem precisamente sobre o aumento da temperatura e a indústria do esqui (Scott e Becken, 2010; Scott, 2011).

Entre os tipos de resposta contam-se, por exemplo, a aquisição de equipamento para a produção de neve artificial, a relocalização para áreas mais elevadas, ou a diversificação das actividades oferecidas. Porém, os mecanismos de adaptação também podem ter consequências indesejáveis. Para além dos óbvios custos financeiros associados à relocalização de estâncias de Inverno, por exemplo, há também consequências ambientais, como o aumento do consumo de energia para a produção artificial de neve, ou o aumento de pressão sobre as regiões de alta montanha, sensíveis do ponto de vista ecológico (UNEP, 2007; Tuppen, 2000).

Em suma, para além da perda de competitividade de alguns destinos turísticos, que as alterações climáticas poderão acarretar, há que considerar possíveis acréscimos de custos, resultantes, por exemplo, da reparação de danos causados por fenómenos extremos, da aquisição de mecanismos ou equipamento adicional para fazer face a situações de emergência, do agravamento de outras despesas (por exemplo seguros, depósitos de armazenamento de água e fontes energéticas autónomas, e interrupções das actividades turísticas - Scott et al., 2009).

\section{Influência do turismo nas alterações climáticas e medidas de mitigação e adaptação}

Impactes do turismo no ambiente e alterações climáticas - Foram sintetizados alguns dos impactes expectáveis das alterações climáticas no turismo. Contudo, também a actividade turística acarreta grandes impactes ambientais, sendo por isso responsável por parte das alterações ambientais actuais (Høyer e Aall, 2005; Gössling, 2005; Frändberg, 2005).

Como enunciado anteriormente, a partir da década de 1960 assistiu-se a uma intensificação do volume de chegadas internacionais, que se fez acompanhar do necessário desenvolvimento de equipamentos e actividades turísticas. A par da emergência do turismo como força económica, na década de 1970 - década de grande impulso do ambientalismo - alguns investigadores começam a apontar evidências dos efeitos ambientais do sector, indicando a ocupação e uso do território, o desenvolvimento de infra-estruturas, a pressão sobre os recursos naturais e a geração de resíduos como fontes de degradação ambiental nas regiões de destino (Williams e Ponsford, 2008).

As sugestões de conceptualização de turismo sustentável multiplicaram-se (Butler, 1999). O conceito proposto pela Organização Mundial do Turismo, em 2001 parte da definição de desenvolvimento sustentável que foi definida e cujos princípios foram estabelecidos no Relatório da Comissão Brundtland em 1987; aí enfatiza-se a necessidade de responder às 
necessidades actuais dos turistas e regiões de acolhimento, sem comprometer as oportunidades futuras. Advoga-se a promoção de uma gestão de recursos que preencha os imperativos económico, social e estético, mantendo a integridade ambiental e cultural (Williams e Ponsford, 2009; Liu, 2003).

Hunter e Shaw (2007), por exemplo, sugerem a generalização do uso da análise da "pegada ecológica" como indicador de turismo sustentável, pois ela fornece uma estimativa da relação entre a quantidade de recursos naturais utilizados e a capacidade de reposição dos mesmos.

Gössling (2002) descreve de forma detalhada as repercussões da actividade turística para cada um dos seguintes campos: alterações na ocupação e uso do solo, no consumo energético e na emissão de gases com efeito de estufa (GEE), na biodiversidade (introduzindo novas espécies, ou induzindo a extinção de espécies autóctones) e na difusão de doenças. O autor demonstra ainda como o turismo pode potenciar mudanças na percepção ambiental dos turistas (Gössling, 2002 e 2005) e introduzir alterações no consumo de recursos hídricos. Gössling (2002) tentou sistematizar os dados existentes, estabelecendo estimativas da escala de impactos relacionados com a prática turística. Ainda que muitas das estimativas avançadas possam falhar - por exemplo, relativamente ao consumo energético e às emissões decorrentes do mesmo, é possível fazer uma estimativa relativa ao transporte (viagem para um dado destino e regresso) e ao destino (alojamento, alimentação), mas desta estimativa está ausente, por exemplo, a energia dispendida na construção das infra-estruturas físicas (alojamentos, acessos) - esta é uma tentativa bastante abrangente.

No âmbito da Segunda Conferência Internacional sobre Turismo e Alterações Climáticas (Davos, Suíça, Outubro de 2007) uma equipa de especialistas da Organização Mundial do Turismo, do Programa das Nações Unidas para o Ambiente (UNEP) e da Organização Meteorológica Mundial formulou uma primeira tentativa de quantificação de emissões de GEE resultantes dos mais importantes subsectores turísticos - transporte, alojamento e actividades realizadas durante a estadia, de que são exemplo as visitas a museus, parques temáticos ou actividades de ar livre, como desportos (esqui, golfe). Este painel estimou a contribuição do turismo para a totalidade de emissões de GEE em cerca de 5\%, em 2005 (Simpson et al., 2008). O transporte aéreo origina, por si só, cerca de $40 \%$ destas. Impõe-se, por isso, que sejam tomadas medidas de mitigação e adaptação pelo sector turístico.

Medidas - De acordo com o Intergovernmemtal Panel on Climatic Change (IPCC (Klein et al., 2007), a mitigação compreende qualquer intervenção que tenha por intuito a redução das concentrações de GEE. De forma muito sumária, com a mitigação pretende-se fazer face às causas das alterações climáticas, enquanto a adaptação é dirigida às consequências por elas induzidas. A adaptação refere-se à capacidade de ajustamento de um sistema natural ou humano a um ambiente novo ou em mudança, de forma a minimizar os potenciais danos, tirar vantagem das oportunidades, ou fazer face às consequências (Klein et al., 2007). $\mathrm{O}$ sucesso das medidas de mitigação pode atenuar a necessidade de adaptação. Respondendo a estímulos climáticos, reais ou expectáveis, ou aos seus efeitos, a adaptação às alterações climáticas pode incluir estratégias de antecipação ou de reacção. Os dois processos têm, contudo, um ponto comum: ambos exigirão estratégias integradas, em que tanto os turistas, como os sectores público e privado têm um papel a desempenhar.

Medidas de mitigação - A tomada de consciência das consequências ambientais do turismo - nomeadamente do peso da actividade no volume de emissões de GEEs - explica que, quer os governos nacionais, quer a comunidade internacional estejam a pôr em marcha políticas de mitigação. De acordo com os resultados da conferência de Davos (Simpson et al., 
2008), as estratégias de mitigação do impacto ambiental do turismo podem ser estruturadas em quatro eixos principais: (i) redução do consumo energético, (ii) aperfeiçoamento da eficiência energética, (iii) aumento do uso de energias renováveis e (iv) sequestro das emissões de GEE através de sumidouros.

i) A redução do consumo energético é o aspecto mais importante da mitigação e pode ser atingido através da alteração na escolha dos destinos e dos meios de transporte e da promoção de estadias mais longas (contrariando a recente tendência de crescimento de short breaks). O encarecimento dos combustíveis pode constituir um constrangimento à procura de destinos de longa distância e ao recurso a meios de transporte dependentes de combustíveis fósseis. Destinos mais próximos dos principais mercados emissores podem vir a beneficiar das reestruturações esperadas.

ii) A aplicação de tecnologias que permitam melhorar a eficiência energética, aplicadas aos meios de transporte ou às estruturas hoteleiras é outra forma de minimizar emissões. A introdução destas tecnologias, no entanto, implica quase sempre longos períodos de tempo, uma vez que exige avultados investimentos. Um sistema de incentivos governamentais, que favoreça a adopção de novas tecnologias, ou de tecnologias que integrem a utilização de energias renováveis pode acelerar este processo.

iii) Vários estudos comprovaram que a adopção de energias renováveis pelo turismo é economicamente viável e vantajosa (Scott et al., 2009). Em alguns destinos insulares, onde o recurso a energias fósseis é caro e sujeito a interrupções no fornecimento, as energias renováveis podem ser a solução e, nalguns destinos, ter um retorno relativamente rápido.

iv) $\mathrm{Na}$ indústria turística o sequestro de emissões faz-se, geralmente, por meio de mecanismos de compensação das emissões de carbono, isto é, assegurando que uma parte das emissões de GEE causados por uma determinada actividade, como um voo, seja compensada através de outra actividade; por exemplo, a reflorestação de um determinado local (Scott et al., 2009).

Estratégias de adaptação - A adaptação no sector da recreação e turismo pode compreender um complexo conjunto de processos e mecanismos - técnicos, comportamentais, empresariais, de gestão, políticos, educacionais - e implica a acção de vários agentes (turistas, operadores e empresários do turismo, associações do sector e instituições governamentais). A vulnerabilidade às mudanças induzidas pelas alterações climáticas é, com efeito, diferente para diferentes tipos de turismo, assim como a capacidade de adaptação o é para os diferentes tipos de stakeholders.

Na perspectiva dos turistas, a adaptação é essencialmente de índole comportamental (Scott et al., 2009, Wilbanks et al., 2007). O turista tem grande liberdade de escolha relativamente ao tipo de turismo (e actividades que lhe estão associadas), ao destino e ao período de tempo em que o quer fazer, podendo facilmente substituir qualquer dos três pressupostos. Embora alguma literatura anteveja mudanças na escolha do destino (Lise e Tol, 2002), vários estudos de impactos das alterações climáticas apontam, sobretudo, no sentido de uma mudança na sazonalidade, beneficiando sobretudo as estações intermédias (Lise e Tol, 2002; Amelung e Viner, 2007).

No que respeita à prática de actividades, também há uma evidente flexibilidade, pois o turista pode facilmente modificar o momento de realização da mesma - condições climáticas 
desfavoráveis não implicam um necessário abandono da actividade e, por vezes, o mero ajuste de vestuário é suficiente. Contudo, a substituição permanente de actividades associadas a um determinado destino também é possível (Scott et al., 2009; De Freitas, 2003).

A capacidade de adaptação dos vários agentes é muito distinta. Se o turista pode adaptar o seu comportamento e a escolha do destino com relativa flexibilidade, o mesmo nem sempre se aplica aos operadores turísticos. O conceito de operador turístico compreende um vasto conjunto de agentes que assegura o planeamento da viagem e o transporte até ao destino turístico pretendido (por exemplo, agências de viagem e empresas de transporte), a hospitalidade (hotéis e outras unidades de alojamento, restaurantes), gestão de equipamentos e de atracções (marinas, casinos, museus, campos de golfe, entre outros) e outros serviços associados à actividade turística (serviços de guia turístico, aluguer de equipamentos, venda de souvenirs). Empresas de recreação e turismo com grandes investimentos em capital fixo (resorts turísticos, campos de golfe, marinas) têm menos capacidade do que agências de viagem ou de transporte, por exemplo. Existem numerosos mecanismos de adaptação técnica e estrutural, que podem ser postos em prática. Por exemplo, em destinos ligados à prática de esqui e outros desportos de neve, grandes investimentos têm sido feitos para assegurar a produção artificial de neve, como já foi referido mais acima (Scott et al., 2009).

Em muitas regiões turísticas, o fornecimento de água é o problema mais premente. A insuficiência do abastecimento de água em regiões de intenso fluxo turístico fica a dever-se, sobretudo, à sobre-exploração dos recursos aí existentes e estima-se que este problema tenda a ser agravado, em face das previsíveis mudanças ambientais.

Os principais mecanismos de resposta ao deficiente abastecimento passam pela criação de reservatórios de água, pelo tratamento de água para reutilização e pela dessalinização (Scott et al., 2009). De acordo com Lazarova et al. (2001) na Europa, a utilização de águas residuais recicladas tem sido aplicada maioritariamente para a irrigação de campos de golfe. Implicando uma extensa ocupação do solo e um considerável consumo de recursos hídricos e energia, a indústria do golfe tem sido alvo de numerosas críticas, que, por seu turno, têm desencadeado progressivas adaptações no sentido de reduzir os impactes ambientais (Brito-Henriques et al., 2010).

Lehman (2010) sublinha que, presentemente, há ainda poucos instrumentos que obriguem os gestores hoteleiros a incluir mecanismos de gestão sustentável dos recursos hídricos, mesmo em ambientes em que se prevê futura escassez de água. Para além disso, a autora aponta a existência de uma diferença essencial entre as várias formas de alojamento, no que toca à gestão dos recursos hídricos: ao passo que nos alojamentos económicos o incentivo de um menor consumo da água passa pela colocação de mensagens de sensibilização para os clientes, nos hotéis mais luxuosos adoptam-se melhores tecnologias para assegurar maior eficiência nos consumos, sem incentivar qualquer mudança de hábitos.

Como Chan e Wong (2006) fazem notar, a adopção de práticas mais eficientes do ponto de vista ambiental deve-se, sobretudo, a três imperativos: a pressão por parte do consumidor (melhoria da imagem da empresa junto do público e dos stakeholders em geral), a redução de custos através do aperfeiçoamento da eficiência tecnológica que permite minimizar consumos e a subordinação às regulações existentes.

A gestão de recursos e territórios está, por norma, entregue aos governos locais e nacionais. As adaptações técnicas passam em grande medida pelas que foram enunciadas a propósito da acção dos operadores turísticos. É importante que a preocupação com os efeitos das alterações climáticas seja incorporada e antecipada no planeamento territorial e económico. 
A protecção do litoral, a regulamentação do desenho urbano e construção, a preparação de planos de emergência, a protecção da vida selvagem e uma boa gestão dos recursos ambientais são medidas essenciais para fazer face aos novos desafios.

Enfatizou-se anteriormente (a propósito de medidas de mitigação) a importância do estímulo da adopção de tecnologias que permitam um menor impacto ambiental, bem como de energias renováveis. Quanto à gestão da actividade, cabe também às instituições políticas estimular e divulgar os vários produtos turísticos existentes. Em face das alterações expectáveis, poderá ser importante, para além dos sistemas de incentivos usuais, criar sistemas de resposta e seguros para extremos climáticos ou catástrofes naturais (Scott et al., 2009, Klein et al., 2007).

\section{CONCLUSÃO}

A história e o estudo das motivações turísticas permitem situar o clima entre os factores que determinam boa parte dos fluxos e tendências de procura turística. A bioclimatologia procurou tornar mais objectivo este vínculo, explicitando as relações entre os vários parâmetros climáticos e o potencial climático-turístico das várias regiões.

O turismo é uma actividade extremamente vulnerável a factores conjunturais, de carácter económico (crises económicas, desemprego, preço dos combustíveis), mas também de carácter social (nomeadamente pressões de grupos de protecção ambiental).

Para além dos efeitos directos que as alterações climáticas possam vir a desencadear no turismo, admite-se que, futuramente, essas alterações podem comprometer o crescimento económico e a estabilidade política de alguns estados. Como já foi enunciado, uma das condições que potenciou a generalização da prática turística foi o aumento dos rendimentos pessoais. Uma contracção no crescimento da economia global pode causar importantes reduções nos rendimentos individuais. Naturalmente, como prática discricionária, não é de surpreender que o crescimento do turismo fique também comprometido numa conjuntura de recessão económica (Scott et al., 2009)

Situações de crise económica favorecem, por sua vez, um aumento da tensão social e da instabilidade política, que em nada beneficiam a procura turística. Assim, estados economicamente mais débeis e onde o turismo assume um peso mais determinante, são passíveis de ser os mais prejudicados pelas alterações climáticas (De Freitas, 2003; Simpson, 2007).

Em face da importância do sector do turismo, como agente promotor de várias actividades económicas, importante fonte de emprego e de valorização dos recursos ambientais e culturais de determinada região, impõe-se que sejam delineados planos de conjunto, de ordem tecnológica ou institucional, que incorporem as medidas de mitigação e adaptação mais adequadas às mudanças climáticas em curso e projectadas para as próximas décadas, como mecanismos de resposta a este desafio.

\section{BIBLIOGRAFIA}

Alcoforado M J, Andrade H, Paulo M J (2004) Weather and recreation at the Atlantic shore near Lisbon, Portugal. A study on applied climatology. In Matzarakis A, De Freitas C R, Scott D (eds) Advances in tourism climatology. Beri- chte des Meteorologishen Institutes der Universitaet Freiburg, 12: 38-48.

Alcoforado M J, Dias A, Gomes V (1999) Bioclimatologia e turismo. Exemplo de aplicação ao Funchal. Islenha, Funchal, 25: 29-37. 
Amelung B, Blazejczik K, Matzarakis A (eds) (2007) Climate change and tourism - assessment and coping strategies. Maastricht -Warsaw - Freiburg.

Amelung B, Viner D (2007) The vulnerability to climate change of the Mediterranean as a tourist destination. In Amelung B, Blazejczik K, Matzarakis A (eds.) Climate Change and Tourism - Assessment and Coping Strategies. Maastricht -Warsaw - Freiburg, 41-55.

Andrade H, Alcoforado MJ, Oliveira S (2007) How does climate effectively affect tourism? The advantage of weather type methodology. In Matzarakis A, de Freitas CR, Scott D (eds.) Developments in Tourism Climatology. Commission on Climate, Tourism and Recreation, International Society of Biometeorology: 74$-79$.

Barry R G, Armstrong R, Callaghan T, Cherry J, Gearheard S, Nolin A, Russell D, Zockler C (2007). Global outlook for Ice and Snow. United Nations Environment Program: 40-62.

Besancenot J P (2001) Climat et santé. Presses Universitaires de France, Paris.

Besancenot J P (1990) Climat et tourisme. Masson, Paris.

Brito-Henriques E, Sarmento J, Lousada M A (2010) When water meets tourism: an introduction. In Brito-Henriques E, Sarmento J, Lousada M A (eds.) Water and tourism. Resources, Management, Planning and Sustainability. Centro de Estudos Geográficos, Universidade de Lisboa: 13-33.

Burki R, Abegg B, Elsasser H (2007) Climate change and tourism in the alpine regions of Switzerland. In Amelung B, Blazejczik K, Matzarakis A (eds.) Climate change and tourism - assessment and coping strategies. Maastricht -Warsaw - Freiburg: 165-172.

Butler R W (1999) Sustainable tourism: a state-of-the-art review. Tourism Geographies, 1(1): 7-25.

Cavaco C (2008) Turismo de saúde e bem-estar. Reinvenção das práticas, renovação dos lugares. In Cavaco C (coord.) Actas do I Seminário Turismo e Planeamento do Território Turismo, Inovação e Desenvolvimento. Centro de Estudos Geográficos, Universidade de Lisboa: 19-64.

Cavaco C, Simões J M (2009) Turismos de nicho: uma introdução. In Simões J M, Ferreira CC (eds.) Turismos de nicho. Motivações, produ- tos, territórios. Centro de Estudos Geográficos, Universidade de Lisboa, Lisboa: 15-39.

Chan E S W, Wong S C K (2006) Motivations for ISO 14001 in the hotel industry. Tourism Management, 27: 481-492.

De Freitas C R (2003) Tourism climatology: evaluating environmental information for decision making and business planning in the recreation and tourism sector. International Journal of Biometeorology, 48: 45-54.

De Freitas C R, Scott D, McBoyle G (2008) A second generation climate index for tourism (CIT): specification and verification. International Journal of Biometeorology, 52: 399-407.

Dias F (2009) Visão de síntese sobre a problemática da motivação turística. Percursos e Ideias, 1(2): 117-143.

Ehmer P, Heymann E (2008) Climate change and tourism: where will the journey lead? In Just $\mathrm{T}$ (ed.) Energy and climate change, Deutsch Bank Research, Frankfurt Am Main, Germany, 28. [Acedido em 9 de Novembro de 2009] http://www.dbresearch.com/PROD/DBR_INTERNET_EN-PROD/PROD0000000000 222943.pdf

Fagence M, Kevan S (1998) Migration, recreation and tourism: human responses to climate differences. In Stanhill G, Dagan B (eds.) Advances in Bioclimatology, vol. 5, Australia, University of Queensland, Springer, 133-156.

Frändberg L (2005) Tourism as victim, problem or solution. Story lines of a complex industryenvironment relation. In Hall C M, Higham J (eds.) Tourism, Recreation and Climate Change. Channel View, Clevedon: 273-285.

Goméz Martin M B (2005) Weather, climate and tourism. Annals of Tourism Research, 32(2): 571-591.

Gössling S (2002) Global environmental consequences of tourism. Global Environmental Change, 12: 283-302.

Gössling S (2005) Tourism's contribution to global environmental change: space, energy, disease, water. In Hall C M, Higham J (eds.) Tourism, recreation and climate change, Channel View Publications, Clevedon: 286-300.

Hoyer K G, Aall C (2005) Sustainable mobility and sustainable tourism. In Hall C M, Higham J (eds.) Tourism, recreation and climate change. Channel View Publications, Clevedon: 260-272. 
Hunter C, Shaw J (2007) The ecological footprint as a key indicator of sustainable tourism. Tourism Management, 28: 46-57.

Klein R J T, Huq S, Denton F, Downing T E, Richels R G, Robinson J B, Toth F L (2007) Inter-relationships between adaptation and mitigation. In Parry M L, Canziani O F, Palutikof J P, van der Linden P J, Hanson C E (eds.) Climate change 2007: impacts, adaptation and vulnerability. Contribution of working group ii to the fourth assessment report of the intergovernmental panel on climate change, Cambridge University Press, Cambridge, UK: 745-777.

Lazarova V, Levine B, Sack J, Cirelli J, Jeffrey P, Muntau H, Salgot M, Brissaud F (2001) Role of water reuse for enhancing integrated water management in Europe and Mediterranean countries. Water Science and Technology, 43(10): 25-33.

Lehman LV (2010) The Challenge for Sustainable Water Management in Tourism Accommodation Enterprises. In Brito-Henriques E, Sarmento J, Lousada M A (eds.) Water and tourism. Resources, Management, Planning and Sustainability. Centro de Estudos Geográficos, Universidade de Lisboa : 13-33.

Liu Z (2003) Sustainable tourism development: a critique. Journal of Sustainable Tourism, 11(6): 459-475.

Lubbe B (1998) Primary image as a dimension of destination image: an empirical assessment. Jounal of Travel \& Tourism Marketing, 7 (4): 21-43.

Lise W, Tol R S J (2002) The impact of climate on tourism demand. Climatic Change, 55(4): 429-449.

Matzarakis A (2006) Weather - and climate - related information for tourism. Tourism \& Hospitality Planning and Development, 3(2): 99-115.

Morgan R, Gatell E, Junyent R, Micallef A, Özhan E, Williams A (2000) An improved user-based beach climate index. Journal of Coastal Conservation, 6: 41-50.

Neves J (2008) As motivações turísticas dos viajantes seniores das Universidades Portuguesas da terceira Idade. In Cavaco C (coord.) Actas do I Seminário Turismo e Planeamento do Território - Turismo, Inovação e Desenvolvimento. Centro de Estudos Geográficos, Universidade de Lisboa: 101-122.
Paulo, M J V (1997) Clima e turismo. Ambiências atmosféricas estivais e conforto na Praia Grande. Tese de Mestrado em Geografia Física. Faculdade de Letras. Universidade de Lisboa.

Perry A H (2005) The Mediterranean: how can the world's most popular and successful tourist destination adapt to a changing climate? In Hall C M, Higham J (eds.) Tourism, recreation and climate change, Channel View Publications, Clevedon: 86-96.

Perry A H (1997) Recreation and tourism. In Thompson R, Perry A (eds.) Applied climatology: principles and practice. Routledge, London: 240-248.

Sarraméa J (1980) Un indice climatico-touristique pour quelques stations balnéaires françaises. Annales de Géographie, LXXXIX (495): 588-604.

Scott D (2011) Why sustainable tourism must address climate change. Journal of Sustainable Tourism, 19(1): 17-34.

Scott D, De Freitas C R, Matzarakis A (2009) Adaptation in the tourism and recreation sector. In McGregor G R, Burton I, Ebi K (eds.) Biometeorology for adaptation to climate variability and change: 171-194.

Scott D, Becken S (2010) Adpating to climate change and climate policy: progress, problems and potentials. Journal of Sustainable Tourism, 18, 3: 283-295.

Simpson M C (2007) Tourism, livelihoods, biodiversity, conservation and the climate change factor in developing countries. In Amelung B, Blazejczyk K, Matzarakis A (eds.) Climate change and tourism - assessment and coping strategies. Maastricht - Warsaw - Freiburg: 190-208.

Simpson M C, Gössling S, Scott D, Hall C M, Gladin E (2008) Climate change adaptation and mitigation in the tourism sector: frameworks, tools and practices. United Nations Environment Programme, University of Oxford, United Nations World Tourism Organization, World Meteorological Organization. Paris.

Tuppen J (2000) The restructuring of winter sports resorts in the french alps: problems, processes and policies. International Journal of Tourism Research, 2: 327-344.

United Nations Environment Program (2007) Global Outlook for Ice and Snow UNEP/GRID-Arendal, Norway ISBN: 978-92-807-2799-9. 
Viner D, Agnew A (1999) Climate change and its impacts on tourism. Climatic Research Unit, Report commissioned for WWF-UK, World Wildlife Fund.

Wall G (2007) The tourism industry and its adaptability and vulnerability to climate. In Amelung B, Blazejczyk K, Matzarakis A (eds.) Climate change and tourism: assessment and coping strategies, Maastricht, Warsaw, Freiburg: 5-19.

Wilbanks T J, Romero Lankao P, Bao M, Berkhout F, Cairncross S, Ceron J P, Kapshe M, Muir-Wood R, Zapata-Marti R (2007) Industry, settlement and society. In Parry M L, Canziani O F, Palutikof J P, van der Linden P J, Hanson C E (eds) Climate change 2007: impacts, adaptation and vulnerability. Contri- bution of working group ii to the fourth assessment report of the intergovernmental panel on climate change, Cambridge University Press, Cambridge, UK: 357-390.

United Nations World Tourism Organization (2010) Tourism Highlights - 2010 Edition. http:// www.unwto.org/facts/eng/pdf/highlights/ UNWTO_Highlights10_en_HR.pdf. [Acedido em 19 de Abril de 2011].

United Nations World Tourism Organization (2002) Tourism 2020 vision - global forecast and profiles of market segments. Volume 7.

Williams P W, Ponsford I F (2009) Confronting tourism's environmental paradox: Transitioning for sustainable tourism. Futures, 41 : 396-404. 